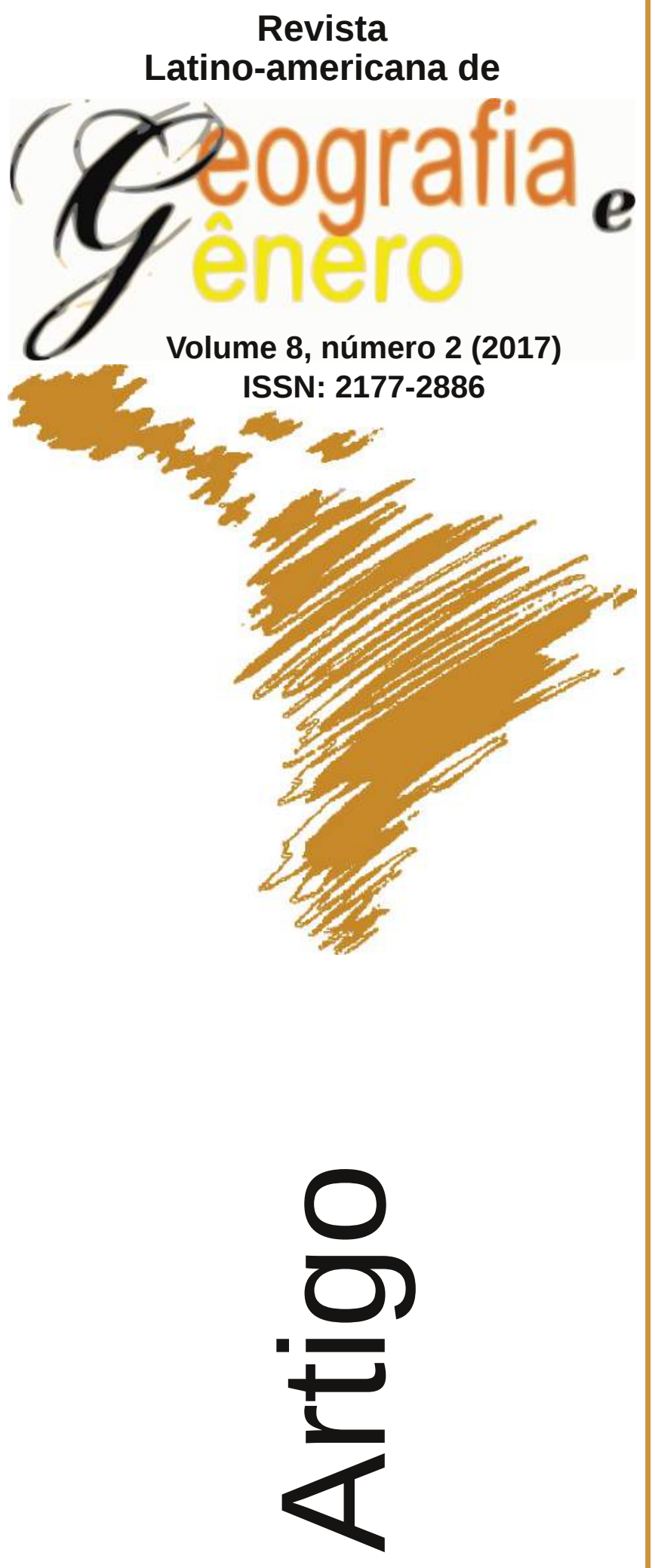

\title{
Desafios Vivenciados por Mulheres Universitárias de Mato Grosso do Sul, que são Mães, Profissionais e Donas de Casa
}

Desafíos Vivenciados por Mujeres Universitarias de Mato Grosso do Sul que son Madres, Profesionales y Amas de Casa

Challenges Experienced by College Women in Mato Grosso do Sul, what are Mothers, Professionals and Housewives

\section{Josiane Peres Gonçalves}

Universidade Federal de Mato Grosso do Sul Brasil

josianeperes7@hotmail.com

\section{Janaina dos Santos Ternovoe}

Universidade Federal de Mato Grosso do Sul Brasil

janaina_elms@hotmail.com

Como citar este artigo:

GONÇALVES, Josiane Peres; TERNOVOE, Janaina dos Santos. Desafios Vivenciados por Mulheres Universitárias de Mato Grosso do Sul, que são Mães, Profissionais e Donas de Casa. Revista Latino Americana de Geografia e Gênero, v. 8, n. 2, p. 116142, 2017. ISSN 2177-2886.

Disponível em:

http://www.revistas2.uepg.br/index.php/rlagg 


\title{
Desafios Vivenciados por Mulheres Universitárias de Mato Grosso do Sul, que são Mães, Profissionais e Donas de Casa
}

\author{
Desafíos Vivenciados por Mujeres Universitarias de Mato Grosso do Sul que \\ son Madres, Profesionales y Amas de Casa
}

\section{Challenges Experienced by College Women in Mato Grosso do Sul, what are Mothers, Professionals and Housewives}

\section{Resumo}

O objetivo do estudo é investigar os desafios vivenciados por mulheres universitárias que também desempenham as funções de donas de casa, mães e profissionais. A pesquisa de campo, de natureza qualitativa, foi realizada por meio de entrevistas semiestruturadas, com 5 (cinco) mulheres, com idade entre 23 a 34 anos, estudantes de cursos de licenciatura. Os resultados foram organizados de acordo com as seguintes categorias: família; trabalho; universidade; relação entre a vida pessoal, acadêmica e profissional. Percebe-se que, apesar das dificuldades e algumas renúncias, as mulheres universitárias conseguem desempenhar suas atividades acadêmicas, evidenciando que não buscam a realização somente para benefício próprio, mas, principalmente, para garantir o conforto de sua família.

Palavras-Chave: Mulheres; Donas de Casa; Mães; Ensino Superior.

\section{Resumen}

El objetivo del estudio es investigar los desafíos vivenciados por mujeres universitarias que también desempeñan las funciones de amas de casa, madres y profesionales. La investigación de campo de naturaleza cualitativa fue realizada por medio de entrevistas semiestructuradas, con 5 (cinco) mujeres, con edades de entre 23 a 34 años, estudiantes de cursos de licenciatura. Los resultados se organizaron de acuerdo con las siguientes categorías: familia; trabajo; universidad; la relación entre la vida personal, académica y profesional. Se percibe que, a pesar de las dificultades y algunas renuncias, las mujeres universitarias logran desempeñar sus actividades académicas, evidenciando que no buscan la realización sólo para beneficio propio, sino principalmente para garantizar el confort de su familia.

Palabras-Clave: Mujeres; Amas de Casa; Madres; Estudios Superiores.

\section{Abstract}

This study aims to investigate the challenges experienced by college women who also perform the functions of housewives, mothers and professionals. The qualitative field research was performed by recording semi-structured interviews with five (5) women, aged 23 to 34 years, students of undergraduate courses. The results were organized according to the following categories: family; recreation; job; university; relationship between the personal, academic and professional life. It is noticed that, despite the difficulties and some waivers, university women can carry out their academic activities, showing that they do not seek success only for their own benefit, but mainly to ensure the comfort of their family.

Keywords: Women; Housewives; Mothers; Higher Education. 
Introdução

Devido às diversas mudanças ocorridas na sociedade, a mulher que, historicamente, não tinha vida pública, gradativamente foi conquistando espaço e participando mais ativamente da vida social. Para que houvesse essa evolução, foi necessário investir em educação, inclusive em nível superior, para que as mulheres se tornassem profissionais aptas a trabalhar nas mais diversas áreas.

Dessa forma, o presente estudo aborda sobre o acesso e participação da mulher no ensino superior que, na atualidade, já se caracteriza como maioria entre os estudantes universitários. O Censo do Ensino Superior de 2013 aponta que 55,5\% dos alunos matriculados nas instituições de ensino superior e 59,2\% dos concluintes são mulheres (BRASIL, 2013). No caso do Campus de Naviraí, da Universidade Federal de Mato Grosso do Sul, no ano de 2015, havia $63 \%$ de mulheres matriculadas e somente $37 \%$ de homens.

Entre as mulheres que cursam o ensino superior, inclusive no Campus de Naviraí, muitas delas desempenham diversas outras funções, como de mães, donas de casa, profissionais que trabalham fora, etc., surgindo o interesse de conhecer a rotina e a realidade dessas mulheres que desempenham múltiplas funções e conseguem avançar em seus estudos acadêmicos. Diante desse cenário, a pesquisa tem por finalidade investigar os desafios vivenciados por mulheres universitárias que, também, desempenham as funções de donas de casa, mães e profissionais.

O interesse pela temática surgiu durante as aulas do curso de Pedagogia, ao ouvir alguns relatos em sala de aula de diversas mulheres que assumiram essa múltipla jornada para estarem nos bancos de uma instituição de ensino superior. Muitas delas interrompem o curso temporariamente, outras pensam e, muitas vezes, acabam desistindo de estudar, enquanto outras, apesar dos inúmeros desafios, são perseverantes e continuam até obter o diploma de graduação.

Acreditamos que, entre outras possibilidades, os resultados da pesquisa poderão contribuir para que a comunidade acadêmica, especialmente os docentes de ensino superior, conheçam as dificuldades vividas por mulheres universitárias que desempenham diversas outras funções, a fim de que possam proporcionar meios para que essas estudantes tenham um bom desempenho e garantia de permanência na universidade.

\section{Mulheres e Acesso ao Ensino Superior no Brasil}

A luta da classe feminina por espaço no cenário educacional ocorreu durante várias décadas no Brasil. De acordo com Rosemberg (2012), longo foi o processo para se permitir o ingresso das brasileiras na educação escolar, sendo autorizada, primeiramente, em 1827 pela Lei Geral do Ensino, mas com restrições apenas às escolas femininas de primeiras letras, entendidas com escolas normais de formação de professores. De acordo com Amado e Bruschini (1988, p. 5):

as chamadas escolas normais, embora a princípio atendessem a uma 
clientela de ambos os sexos, o que era inovador para a época, logo passaram a apresentar frequência predominantemente feminina. Ao se formar, as novas mestras ou iam dar aula nas poucas vagas existentes no primário para meninas ou, mais frequentemente, eram contratadas como preceptoras ou professoras particulares, nas casas ou fazendas de famílias abastadas.

Vale ressaltar, porém, que foi um processo gradual e que eram poucas as escolas que aceitavam alunas do gênero feminino, sendo que a educação era diferenciada da dos meninos, conforme relata Freire (2011, p. 244):

as escolas de primeiras letras, no entanto, apareceram de forma esparsa, sendo, a maior parte delas, destinadas aos meninos. Algumas poucas escolas funcionavam com meninas. Para as meninas, tinha-se uma professora e para os meninos, professores. A escola brasileira iniciava sua organização com a separação por sexo e a educação era pensada de forma diferenciada para meninos e meninas.

Nesse sentido, Louro (1997) destaca que havia um discurso que agradava a muitos grupos sociais em que se entendia que a mulher deveria ser mais educada do que instruída, ou seja, a educação moral vinha em primeiro plano com algumas poucas e pequenas doses de instrução. Assim, o destino primordial da mulher era o seio familiar e, para isso, ela precisaria ser apenas a mãe virtuosa, o pilar de sustentação do lar e a educadora das futuras gerações.

Rosemberg (2012, p. 334), ao comentar sobre a educação escolar para mulheres, enfatiza que havia "[...] o ideário de que a educação de meninas e moças deveria ser mais restrita que a de meninos e rapazes em decorrência de sua saúde frágil, sua inteligência limitada e voltada para sua 'missão' de mãe". Complementa afirmando que, também, havia o "[...] impedimento à continuidade dos estudos secundários e superior para jovens brasileiras" ( $p$. 334).

Louro (1997) comenta que à mulher era atribuído o fracasso ou o sucesso de uma sociedade, pois partia dela a instrução de seus filhos e tudo quanto saísse dos conceitos sociais daquela época era considerado um relapso de sua parte. A autora justifica que tal ideia foi "[...] exposta na primeira lei de instrução pública do Brasil, de 1827" (p. 447).

Nas décadas de 1830 a 1840 , quando foram criadas as escolas normais públicas na cidade do Rio de Janeiro, as escolas só podiam receber o público masculino. Rosemberg (2012) destaca que, apesar de muitos transtornos, conseguiu-se a permissão para a entrada de mulheres na instituição, entretanto, mantinha-se a segregação sexual, pois a frequência de homens e mulheres na escola era feito em dias, períodos, prédios separados ou alternados.

Nessa época, a convivência de meninos e meninas em um mesmo espaço era uma prática condenável pela Igreja Católica e, até mesmo, pelo ideário positivista que se alastrava no país no século XIX, conforme explica Rosemberg (2012). No entanto, atribui-se as missões protestantes em 1850 na província de São Paulo a abertura de escolas mistas, mas, o que se sabe é que a 
origem dessa miscigenação deu-se por motivos econômicos, pois, para o governo era muito caro manter dois sistemas de ensino. Um século mais tarde, a Igreja Católica inaugurava nas pequenas cidades classes mistas frente ao número reduzido de estudantes:

Tantas atribulações e restrições permitem entender porque a primeira brasileira a dispor de diploma de ensino superior, Maria Augusta Generosa Estrela, graduou-se, em 1882, em Medicina, nos Estados Unidos e não no Brasil: foi apenas em 1879 que a Lei Leôncio de carvalho garantiu às mulheres o direito de estudar em instituições brasileiras de ensino superior. Setenta e nove anos após a fundação da primeira instituição de ensino superior no país, a Branca Rita Lobato graduou-se na Faculdade de Medicina da Bahia (ROSEMBERG, 2012, p. 337).

Como afirma Rosemberg (2012), apenas em 1926, um período de quase trinta anos, a negra Maria Rita de Andrade conquista o título de bacharel pela faculdade de Direito da Bahia. Embora fosse difícil a mulher se destacar no cenário acadêmico, houve outras mulheres que conseguiram o feito nessa época, como: Nísia Floresta (1809-1885), escritora, jornalista e educadora feminista. E suas sucessoras Bertha Lutz (1894-1976), Maria Lacerda de Moura (1887-1945), entre outras.

Somente em 1971, com a Lei de Diretrizes e Bases da Educação, conseguiu-se romper as últimas barreiras legais que atribuiu equivalência entre os cursos secundários. Assim, Rosemberg (2012) ressalta que foi a partir desse período que o curso normal secundário, ramo estritamente feminino desde o final do século XIX, passa a não ser mais discriminado por ser apenas profissionalizante e vem a possibilitar o acesso ao ensino superior.

A referida autora também menciona que outra barreira da educação formal e pública rompida no transcorrer desse percurso foi a que proibia a segregação sexual no ambiente escolar. Mesmo com a promulgação da lei em 1971, havia uma resistência muito grande, mesmo quando se tratava da formação de mestras. Com o surgimento dos movimentos feministas, grandes lutas foram travadas no sentido de garantir a inserção da mulher no cenário social e educacional. Embora apenas a partir de 1975 tenham surgido os primeiros textos abordando a situação educacional de homens e mulheres, demonstrando de maneira crítica o sexismo observado em práticas educativas e fazendo um balanço das contribuições das Ciências Humanas para compreender a condição feminina e relacionar a educação das mulheres e a sua participação na vida econômica e o acesso ao ensino superior. Segundo Rosemberg (2012, p. 348):

humildes iniciativas, humildes resultados diante do intenso acesso de mulheres ao sistema de ensino brasileiro, principalmente após os anos de 1960. Durante séculos, o Estado brasileiro fora eficiente em manter as mulheres afastadas da educação pública. Depois, sem as antigas restrições e impulsionadas por mudanças econômicas e culturais (aí incluindo o feminismo), as mulheres vêm dando conta do recado por 
sua conta e risco, isto é, mesmo sem políticas de ação afirmativa: aproveitam as brechas do sistema, educam-se.

Observa-se que, embora historicamente tenha prevalecido nas universidades brasileiras a predominância androcêntrica, a partir dos anos de 1970 houve um aumento significativo e rápido da entrada das mulheres no ensino superior. "Nesse curto período, as mulheres conseguiram reverter um quadro de desigualdade histórica e consolidar uma nova realidade, em que são mais escolarizadas que o contingente masculino" (GUEDES, 2008, p. 118).

Após a introdução do Ministério da Educação (MEC), em 1990, de indicadores de diferenciais de avaliação de estudantes, tais como: Sistema de Avaliação da Educação Básica (SAEB), Programa Internacional de Avaliação de Alunos/ Program for International Student Assessment (PISA), Exame Nacional do Ensino Médio (ENEM), Exame Nacional de Cursos (ENC), observou-se que, em média, as mulheres têm melhores resultados que os homens nessas provas, principalmente em Português (ROSEMBERG, 2012).

É interessante notar que, conforme Louro (1997), logo que as mulheres começaram a estudar os cursos normais, muitos questionavam a capacidade feminina para educar crianças, especialmente por se entender que as mulheres não tinham muitas condições cognitivas. Assim, ao basear-se em Safioti (1979), ela ressalta que "[...] alguns poderão afirmar que se constitui uma 'temeridade', numa 'insensatez' entregar às mulheres - portadoras de cérebros 'pouco desenvolvidos' pelo seu 'desuso' - a educação das crianças” (LOURO, 1997, p. 78). Ou seja, se inicialmente a capacidade intelectual das mulheres não era reconhecida, as avaliações educacionais na atualidade têm evidenciado que elas são tão capazes e muitas vezes se sobressaem aos homens:

A educação das mulheres entrou na agenda da educação nacional dos anos de 1990 quando o Brasil, como outros países da América latina, viveu um intenso processo de reformas educacionais impulsionadas por organizações internacionais (UNESCO, UNICEF, Banco Mundial, entre outras), subsumidas nos compromissos da campanha "Educação Para Todos" (ROSEMBERG, 2012, p. 345).

No Brasil, essas reformas tenderam a diferentes frentes, proporcionando a elaboração de novos parâmetros curriculares nacionais para o ensino fundamental e médio. E, no governo de Luiz Inácio Lula da Silva, foram criados Planos Nacionais para as Mulheres em duas conferências nacionais (em 2004 e em 2007), denominadas pelo ministério da Educação de Secretaria de Educação Continuada, Alfabetização e Diversidade (SECAD) os dois planos tinham por objetivo garantir matrícula e eliminar conteúdos sexistas e discriminatórios. Para Rosemberg (2012), estudos sobre relações de gênero também demonstraram que essa disparidade de resultados só se efetiva em casos de rendimento familiar, "cor/raça", região e local de residência. Ou seja, quando o indivíduo precisa trabalhar para se manter e mora em lugares com poucas oportunidades de estudo, suas chances de subir nos índices de desenvolvimento escolar se tornam cada vez menores. 
O governo tem lançado programas sociais para reduzir a competitividade no mercado de trabalho, com políticas de ações afirmativas via sistema de cotas, pode estar contribuindo com que mais homens venham vislumbrar a progressão escolar. Isso se efetiva na discriminação que a mulher sofre no mercado de trabalho, fazendo com que a mulher seja maioria em áreas da educação enquanto estudante, professores e trabalhadores e esse cenário de justifica por condições exteriores a escola:

A igualdade de oportunidades é buscada ao longo dos séculos, sendo uma das principais preocupações de grupos feministas. A situação de reconhecimento da necessidade de ações afirmativas origina-se do reconhecimento de um caso específico, de uma situação particular de uma minoria ou de determinado grupo em situação de desvantagem que sofre discriminação (COZER, CORINO e PÊPE, 2008, p. 02).

Segundo Barsted e Pitanguy (2011), a Organização para a Cooperação e o Desenvolvimento Econômico (OCDE) aponta que as carreiras de Engenharia, Produção e Construção permaneceram predominantes do sexo masculino (72\% X 28\%) e a área de Educação se mantém feminina (70,4\% X 29,6\%), alguns cursos vêm alterando seu perfil e um deles é o da saúde.

Ao analisar o aumento da proporção feminina nas universidades brasileiras nas últimas três décadas do século XX, Guedes (2008) constatou que, entre o total de estudantes universitários, 25,6\% eram mulheres em 1970, ampliando para 52,8\% no ano 2000. Porém, aumentou o número de mulheres em cursos que, historicamente, foram vistos como masculinos (Arquitetura, Direito, Medicina, etc.), mas, não houve a entrada de homens em cursos que, historicamente, foram vistos como femininos (Enfermagem, Pedagogia, Serviço Social, etc.), cujas profissões estão associadas ao cuidar de pessoas, como se fossem extensão da maternidade.

Em 1970, entre o total de estudantes de Arquitetura, 17\% eram mulheres e no ano 2000 ampliou para 54\%. Enquanto que no curso de Pedagogia, 84\% eram mulheres em 1970 e no ano 2000 ampliou para 93\%. O curso de Ciências Sociais (que, juntamente com Pedagogia, faz parte do presente estudo), não teve muita variação no número de mulheres, uma vez que elas representavam $72 \%$ do total de universitários em 1970, ampliando para $78 \%$ no ano 2000 (GUEDES, 2008).

É possível perceber que as universidades se caracterizam por um espaço geográfico permeado por relações de gêneros e, nesse sentido, o fenômeno relativo ao aumento de mulheres universitárias está associado aos estudos das geografias feministas ou de gêneros, uma vez que "[...] a geografia feminista quer compreender como o sujeito feminino é construído dentro das estruturas de dominação sócio-espaciais" (SILVA, 2003, p. 37).

Ao considerar as universidades como estruturas de dominação masculina, historicamente construídas, as mulheres tiveram que lutar por seus direitos para entrar nas universidades, da mesma forma em que na Geografia foi necessário lutar para inserir o universo feminino nas produções investigativas. Nesse sentido, Silva (2010, p. 42) argumenta que as geógrafas feministas 
tiveram consciência de que não podiam fugir completamente à ciência androcêntrica, então, tiveram que pensar por meio das "[...] fissuras dos quadros conceituais e ter a consciência da geopolítica do conhecimento estruturadas na diferença colonial e sexual epistêmica".(SILVA, 2010, p. 42).

A autora destaca que as geografias feministas consideram as dimensões espacial e temporal ao analisar as experiências da vida cotidiana e concreta das pessoas. "O espaço, nesse sentido, compõe o gênero performático, mas também os atos subjetivados que se diferenciam do ideal de gênero, jamais realizável em sua concretude" (SILVA, 2010, p. 43).

Embora nos espaços universitários as mulheres estejam cada vez mais se inserindo e demonstrem competência para atuar em áreas que são vistas socialmente como masculinas, a maioria das universitárias costuma optar por cursos na área de Ciências Humanas, talvez por enfrentar menos preconceito, tanto no processo de formação acadêmica, quanto no exercício da profissão. Assim, o acesso à Universidade, especialmente em cursos de Ciências Humanas, torna-se uma válvula de escape para muitas mulheres que almejam o tão sonhado diploma de ensino superior e, consequentemente, a ascensão na carreira profissional e aumento da renda familiar.

\section{A Dona de Casa}

Um aspecto importante da trajetória da mulher burguesa do século XIX é que, ao contrair matrimônio, a união era para a vida toda, se sujeitando ao marido, sendo sempre a mulher ordeira e submissa. Cuidar dos afazeres domésticos, das finanças e dos filhos era sua principal responsabilidade, estando ela zelando pelo bom andamento doméstico e pela educação dos filhos, desempenharia seu melhor papel, já que, socialmente, as mulheres obtinham seu reconhecimento social se fossem apresentadas como 'boas donas de casa' (PINSKY, 2012). Ao marido cabia-lhe a responsabilidade de ser o provedor e mantenedor da família, sendo para ele honra sua esposa não trabalhar fora e apenas cuidar do lar e dos filhos. Como expressa uma revista de 1950, com normas de condutas de uma boa dona de casa trazidas por Xavier Filha (2003, p. 64) ao analisar trechos de artigos da revista:

Ser boa dona de casa é ser um a boa esposa, ou seja, alguém prestativa, cuidadosa, carinhosa, orgulhosa do que faz 'serena, organizada e econômica', alguém que desempenha as tarefas domésticas com apreço e, especialmente, é o exemplo da esposa ao receber os convidados nos serões, além de estar sempre bela e elegante para acompanhar o marido em suas atividades sociais.

Com o passar do tempo, a modernidade foi chegando ao lar das famílias que passavam a contar com eletricidade, gás e água encanada e tudo isso trouxe melhorias a vida das donas de casa, os ambientes ficaram mais limpos, os alimentos e água livres de contaminação os móveis menos empoeirados e as roupas menos encardidas. Os lares ganharam chuveiros, privadas, descargas, lâmpadas e o crescimento industrial trouxe o barateamento das roupas, 
livrando as donas de casa de terem que confeccioná-las (PINSKY, 2012).

Contudo, com tantas facilidades a dona de casa não foi eximida de suas obrigações, ao contrário, elas agora deveriam contar com certo requinte já que as facilidades lhe trouxeram maior tempo para se dedicar aos ornamentos da casa e à preparação de um cardápio mais elaborado. Socialmente, novos critérios passam a fazer parte de um bom desempenho de uma 'boa dona de casa', já que a aparência do interior da casa ganha destaque e se torna vitrine de status da família e para as visitas. Conforme Pinsky (2012, p. 500), a “[...] dona de casa perfeita expressa na sua casa sinais de suas prendas com toalhas de crochê, almofadas, cortinas, etc., sendo que o lazer se resume em cuidar dos filhos e costurar".

Tendo em vista que o dinheiro é uma das principais causas de atritos entre os casais, o controle financeiro, por parte da dona de casa, é de primordial importância, evitando, por muitas vezes, a situação humilhante de ter que pedir dinheiro ao marido para despesas extras, e como não trabalhava fora não tinha o direito de cobrar de seu marido além do que ele pode lhe oferecer:

A 'boa dona de casa' amolda-se à mesada estabelecida pelo marido de acordo com os meios que dispõe o casal e jamais o censura pelo fato de não ganhar o suficiente. O perfil da mulher 'gastadeira' contrapõese ao da 'boa dona de casa', ajudando a defini-la. Outras imagens que fazem o mesmo são: a 'dona de casa mal-humorada', a 'egoísta' (que solicita a participação do marido no serviço doméstico) e a 'preguiçosa' (PINSKY, 2012, p. 502).

No início do século XX, a participação da mulher no mercado de trabalho deu-se em fábricas e, embora o trabalho fosse considerado mais respeitoso que de uma prostituta, não lhe garantia uma maior consideração, tanto quanto a de uma mulher que se dedicava exclusivamente ao lar. Tinha seu salário menor que de um homem por ser considerada força de trabalho menos capacitada e vindo a perder o emprego ao casar-se e engravidar. As fábricas eram vistas como lugares de perdição, tanto de solteiras quanto de casadas, devido às longas jornadas de trabalho, a falta de higiene e o assédio sexual frequente faziam com que elas se desviassem de suas 'funções naturais'. Para Pinsky (2012, p. 503), “a atividade fabril não é para o sexo feminino, doméstico e maternal por natureza. A fábrica assim como o bordel, não é local moralmente adequado 'à mulher de bem'".

Pinsky (2012) relata que, em 1930, o número de mulheres nos parques industriais teve um declínio, fato que contribuiu para que as indústrias se tornassem um espaço masculino por excelência. E, para as mulheres pobres daquela época, restavam apenas as funções consideradas femininas como: empregada, doméstica, lavadeira, cozinheira. Com o fato de as mulheres, agora, adquirirem alguma renda, dava-lhes certa independência financeira em relação a seus pais ou companheiros, embora isso contrariasse a ideologia dominante. Uma opção para aquelas mulheres que mantinham o interesse de ajudar na renda familiar era o trabalho como costureira, o qual fornecia as peças para as fábricas e lojas, sendo assim, dava a impressão de não deixar o 
ambiente familiar nem os afazeres domésticos e o cuidado com os filhos.

Contudo, a mulher que tivesse algum tipo de remuneração já era considerada em estado de vulnerabilidade perante a sociedade, sendo ela de qualquer posição social, ou seja, para exercer determinadas profissões, como costureira ou florista, a mulher tinha que se submeter ao julgamento público e provar uma conduta irrepreensível (PINSKY, 2012). Na primeira metade do século XX, as mulheres com escolaridade e que exercessem profissões como: professora, enfermeira, secretária e balconista sofriam menos censura da oposição, devido ao caráter de suas profissões remeter a cuidado, assistência e serviço. Já para as mulheres que decidissem pelo magistério, não se eximiam de censuras e repreensões, desse modo, deveriam manter a feminilidade e a moral, servindo de exemplo para alunos e alunas que tinham, nela, o reflexo de uma mãe.

Com uma pequena mudança no século $\mathrm{XX}$ da mulher no mercado de trabalho, os brasileiros já demonstravam uma melhora no nível de escolaridade, com destaque para a população feminina, que já tinha sua mão de obra melhor valorizada. Nos anos de 1950, a participação da mulher no mercado de trabalho teve um crescimento considerável, momento esse em que as mulheres puderam competir de forma igualitária nas categorias profissionais, dando às mulheres direitos como: direitos trabalhistas, horários fixos de trabalho, férias remuneradas, folga nos fins de semana, podendo, dessa forma, separar o trabalho do lazer.

O trabalho, além dos afazeres domésticos, trouxe para as mulheres um poder de decisão no orçamento da família, proporcionando-lhes uma maior participação no cenário social antes apenas masculino.

Para muitas mulheres das camadas médias, o desejo de trabalhar e de independência financeira convivia com o ideal de 'rainha do lar'. Isso porque, de um modo geral, o marido continuava ocupando o status de 'chefe da casa', sendo que o trabalho remunerado da esposa, se este existisse, era visto como subsidiário ao do marido (PADILHA e SANTOS, 2014, p. 77).

Entretanto, a batalha não estava de toda vencida, pois, os conservadores sociais trataram de forma negativa a emancipação feminina, alegando que as mulheres abandonaram o lar, deixaram homens sem emprego e que o trabalho era apenas para satisfação do luxo e da vaidade.

[...] - ao 'abraçar as vantagens materiais' de uma profissão, comprometem a feminilidade, o respeito dos homens e os 'privilégios de seu sexo'; renunciam aos agrados e carinhos e dão à sua existência 'um sentido vão e estéril'; deixam o aconchego do lar para adentrar em 'um mundo competitivo e cruel'. A 'mulher que trabalha', frequentemente é 'infeliz e frustrada' (PINSKY, 2012, p. 508).

De todo modo, se ainda assim a mulher quiser manter-se no trabalho, ela deve procurar ser feminina, demonstrando delicadeza e ternura, zelando pela 
sua integridade moral. O emprego não deve abalar em nada o que o namorado, o noivo e o marido procuram na eleita do seu coração. Segundo Pinsky (2012, p. 508):

mesmo com a maior aprovação social da 'mulher que trabalha', essa figura continuava hierarquicamente inferior à da 'boa esposa', mãe e 'dona de casa ideal'. Para muitos, casamento e trabalho são incompatíveis, não só porque o envolvimento profissional prejudica a dedicação a casa e família, mas também porque 'os homens não gostam de mulheres independentes'. Emprego é para as solteiras; carreira para as 'solteironas'. A independência feminina obtida com o trabalho mais bem remunerado cria mulheres 'duronas', 'frias', 'incapazes de amar', 'casadas com o trabalho' (grifos do autor).

Por esse motivo uma das formas de afastar as mulheres do setor trabalhista era as amedrontando de que sua melhor qualificação profissional poderia afastar seu marido, fazendo com que ele tivesse um relacionamento extraconjugal e, sem uma empregada doméstica para ajudá-la, ela estaria sobrecarregada com as tarefas domésticas. Nessa época, a carga dos males sociais continuava sobre os ombros femininos, e tudo dependia da atuação da mulher como mãe e dona de casa. Em 1950 e 1960, ambos o sexos se aproximavam do que, atualmente, é conhecido como ensino médio, contudo, as moças seguiam por trajetórias de menos prestígio que os rapazes e, grande parte delas, optava pelo magistério que ficava articulado com a missão da mulher do lar. Para aquelas que almejavam a Universidade, era exigido que mantivesse a feminilidade, pois, se acreditava que uma mulher com um grau de instrução elevado teria mais dificuldade em contrair matrimônio, tornandose exigente e ofuscando o brilho do marido.

Apesar de tantos impasses enfrentados pela classe feminina, é notório o aumento da participação da mulher no setor empresarial, contudo, sua jornada de afazeres domiciliares continua permanente, conforme apontam Campos e Teixeira (2009, p. 25):

a participação das mulheres no mercado de trabalho vem crescendo no Brasil nos últimos anos. Segundo o IPEA (2008), se, em 1996, $46 \%$ da população feminina estava ocupada ou à procura de emprego, esta proporção sobe para 52,6\% em 2006, mas ainda de forma significativamente inferior à participação dos homens, que atingiu $72,9 \%$ neste mesmo ano. Esse quadro diminui o número de mulheres dedicadas em tempo integral às atividades familiares, bem como a carga horária semanal de trabalhos domésticos, mas não tem eliminado o grande tempo de ocupação das mulheres nestas atividades, mesmo trabalhando fora do lar, e assim caracterizando a dupla jornada de trabalho para as mulheres (entre as ocupadas, 92\% declararam cuidar dos afazeres domésticos). 
O progresso das mulheres, nos dias atuais, deve-se ao movimento feminista que, de acordo com Santos e Sacramento (2011), contribuiu para muitas das conquistas dos últimos 150 anos. A mulher atual tem ido à busca de seu espaço, deixando pra trás aquela imagem do passado:

A mulher atual passou a conduzir suas ações e se tornou multifuncional, bem resolvida, tendo em primeiro lugar sua liberdade e uma melhor condição de vida, sem deixar de lado sua feminilidade. Mais que isso, assegurou seu direito à cidadania, legitimando seu papel enquanto agente transformador. Sua participação nas últimas seis décadas tem sido um dos fatos mais marcantes ocorridos na sociedade brasileira: Entre os brasileiros que trabalham, as mulheres são quase a metade, e são responsáveis pelo sustento de aproximadamente $33 \%$ das famílias no Brasil. Tudo isso conseguido inicialmente quando nos fins dos anos 60 foi franqueado a elas o ensino popular (SANTOS e SACRAMENTO, 2011, p. 07).

Com o crescimento do número de famílias sendo chefiadas por mulheres, diminuiu o estigma de que a mulher é incapaz de suprir o sustento de sua casa, zelar pelos cuidados do lar e da educação dos filhos. Essa é a imagem da mulher do século XXI, polivalente e que vai à busca dos seus ideais, pensando no que é melhor para si e sua família.

As mulheres dedicam-se tanto ao trabalho quanto o homem e, quando voltam para casa, dedicam-se com a mesma intensidade ao trabalho doméstico. Embora alguns homens ajudem em casa, não chegam nem perto da energia que a mulher tende a dar (PROBST, 2015, p. 04).

Por outro lado, encarar o desafio de trabalhar fora com a maternidade não é tarefa fácil. Muitas mães se sentem culpadas por não ter condições de ficar muito tempo com os filhos, conforme aponta Spindola e Santos (2003, p. 594): "esse sentimento encontra forte relação na cultura e no processo de educação e socialização do indivíduo", e está atrelado ao papel da boa mãe e das responsabilidades maternas. Outras, ainda se deparam com outros desafios, de ter que trabalhar fora, cuidar da casa e, ainda, estudar, na maioria das vezes porque não tiveram condições de prosseguir com os estudos no momento oportuno, optando por voltar a estudar quando já têm filhos. Esse é o desafio vivenciado por muitas mulheres, como as que fizeram parte do presente estudo, cujos resultados serão analisados na sequência, após a explicação sobre a metodologia da pesquisa.

\section{Metodologia}

Além da pesquisa bibliográfica, e diante do objetivo do estudo, foi realizada, também, uma pesquisa de campo de natureza qualitativa. Para Minayo (1998, p.10-11), a pesquisa qualitativa incorpora a questão do significado e da intencionalidade como inerentes aos atos, às relações e às 
estruturas sociais, considerando a subjetividade como fundante de sentido e como constitutiva do social. Sua preocupação é explicar os meandros das relações sociais, consideradas essência e resultado da atividade humana criadora, afetiva e racional, que pode ser apreendida através do cotidiano, da vivência e da explicação do senso comum. Assim, o significado é o conceito central da investigação, e a tarefa do pesquisador é buscar a compreensão da realidade humana vivida socialmente, aprofundando-se no universo dos significados das ações e relações humanas.

Portanto, esta pesquisa assume os moldes qualitativos, pois, busca compreender de maneira espontânea e subjetiva o entrevistado, visando entender seus sentimentos, percepções, intenções, comportamentos passados, entendimento de razões, significados e motivações. Assim, foram elaboradas questões que proponham extrair quais os desafios e as representações das mulheres que são donas de casa e mães e que frequentam o ensino superior. Para a coleta dos dados foram realizadas entrevistas do tipo semiestruturadas, oferecendo liberdade para as respostas das entrevistadas.

Segundo Lüdke e André (1986, p. 34), esse modelo de pesquisa, a partir de entrevistas semiestruturadas, “[...] permite a captação imediata e corrente da informação desejada, praticamente com qualquer tipo de informante e sobre os mais variados tópicos".

Os sujeitos da pesquisa foram cinco mulheres donas de casa e mães que frequentavam o ensino superior na Universidade Federal de Mato Grosso do Sul. Os critérios para a escolha das participantes deu-se por mulheres que fossem casadas ou solteiras e que tivessem idade acima de 20 anos, com filho(s), que tivessem emprego formal e que fossem acadêmicas da Universidade Federal de Mato Grosso do Sul, no campus de Naviraí / CPNV, nos cursos de Ciências Sociais e Pedagogia. Para tal, foram selecionadas mulheres de semestres diferentes de ambos os cursos, buscando a subjetividade de cada entrevistada. Por meio do Quadro 1 são evidenciadas as principais características das participantes da pesquisa, cujos nomes são fictícios para preservar a identidade das entrevistadas:

Quadro 1: Perfil das Participantes da Pesquisa.

\begin{tabular}{|c|c|c|c|c|c|}
\hline Identificação & $\begin{array}{c}\text { Idade } \\
\text { (anos) }\end{array}$ & $\begin{array}{c}\text { Configuração } \\
\text { Familiar }\end{array}$ & Profissão & $\begin{array}{c}\text { Curso de } \\
\text { Graduação }\end{array}$ & Semestre \\
\hline Dália & 34 & $\begin{array}{c}\text { Casada, 1 filho de } \\
7 \text { anos e 1 filha de } \\
12 \text { anos }\end{array}$ & Professora & $\begin{array}{c}\text { Ciências } \\
\text { Sociais }\end{array}$ & $1^{\text {o }}$ \\
\hline Gardênia & 31 & $\begin{array}{c}\text { Casada, } 1 \text { filho de } \\
13 \text { anos }\end{array}$ & $\begin{array}{c}\text { Funcionária } \\
\text { Pública }\end{array}$ & $\begin{array}{c}\text { Ciências } \\
\text { Sociais }\end{array}$ & $3^{\text {o }}$ \\
\hline Hortência & 32 & $\begin{array}{c}\text { Casada, 1 filha de } \\
15 \text { anos e 1 filho } \\
\text { de } 11 \text { meses }\end{array}$ & Secretária & Pedagogia & $1^{\text {o }}$ \\
\hline
\end{tabular}


Desafios Vivenciados por Mulheres Universitárias de Mato Grosso do Sul, que

são Mães, Profissionais e Donas de Casa

\begin{tabular}{|c|c|c|c|c|c|}
\hline Margarida & 28 & $\begin{array}{c}\text { Solteira, } 1 \text { filha } \\
\text { de } 10 \text { anos }\end{array}$ & $\begin{array}{c}\text { Auxiliar de } \\
\text { escritório }\end{array}$ & Pedagogia & $5^{\circ}$ \\
\hline Rosa & 23 & $\begin{array}{c}\text { Solteira, } 1 \text { filho } \\
\text { de } 7 \text { anos }\end{array}$ & $\begin{array}{c}\text { Atendente e } \\
\text { estagiária }\end{array}$ & Pedagogia & $7^{\circ}$ \\
\hline
\end{tabular}

Fonte: Ternovoe, 2015.

Vale ressaltar que todas as participantes foram previamente informadas sobre as finalidades e procedimentos da pesquisa, sendo agendado, previamente, horário para a realização das entrevistas. Por fim, os dados foram transcritos, sistematizados para, então, serem analisados, conforme apresentados na sequência.

\section{Resultados e Discussão}

Os resultados da pesquisa foram organizados em cinco categorias, tais como: família; lazer; trabalho; Universidade; relação entre a vida pessoal, acadêmica e profissional. Os dados são apresentados e analisados, na sequência, sendo fundamentadas em autores diversos.

\section{Família}

Ao serem questionadas sobre a reação da família ao saber do seu ingresso na Universidade, todas responderam que obtiveram total apoio dos seus familiares:

Como eu já estou na segunda faculdade, a reação foi a mesma da primeira: "você é doida, você não tem idade pra isso, você tá velha, seus filhos vão ficar sozinhos em casa"... Isso da parte dos familiares, eu digo assim, pai, irmãos, no caso a minha mãe quando estava viva... Já do meu marido eu tenho tido total apoio (DÁLIA).

Ah, sim, bom, eles sempre me incentivaram em tudo que eu quis fazer na minha vida. Tudo que eu quis fazer é assim, que fosse algo de mudança, algo que fosse pra benefício meu, né? Eles sempre me incentivaram muito, em todos os quesitos, não só de estudo, mas, qualquer quesito que seja, que eu tomo uma decisão e eles sempre me apoiam. Então, assim, pra eles assim, foi o máximo né? Porque tanto tempo parada, tanto tempo sem fazer nada, sem cursar nada e, de repente, agora, eu falar "vou fazer" e vim e fazer. Eles acharam muito bom (MARGARIDA).

[...] É muito orgulho né? Tanto meus pais quanto meus irmãos, eles assim... Apoiam grandemente. Meu filho tem muito orgulho de dizer que a mãe dele estuda ainda (GARDENNIA).

Um ponto importante na resposta da entrevistada Dália é que, mesmo em pleno século XXI, o pensamento de algumas famílias em relação à instrução da 
mulher não sofreu muitas mudanças, visto que alguns membros da família consideram Dália insana por querer frequentar os bancos acadêmicos, por considerá-la velha e omissa quanto aos filhos e a vida doméstica. Esse relato reforça o que afirma Louro (1997), a mulher cabe apenas ser instruída no que diz respeito aos afazeres domésticos e à educação dos filhos. Já a entrevistada Margarida, que é solteira e tem uma filha, não encontrou nenhuma objeção dos familiares quando quis ingressar na Universidade, talvez pelo fato de a família acreditar que, com maior nível de escolaridade, ela terá possibilidade de oferecer melhores condições de vida para sua filha.

Questionadas sobre possíveis mudanças na rotina da família após o ingresso na Universidade, apenas uma das entrevistadas respondeu que não houve, porque ela sempre estudou, fazendo cursinhos noturnos para concurso público e já está no segundo curso de graduação. Ao contrário, as outras entrevistadas relataram mudanças significativas na rotina da família. A entrevistada Margarida, por exemplo, que é solteira, relata mudanças nos horários de trabalho e das privações com os finais de semana por conta dos trabalhos acadêmicos. Embora Margarida relate muitas mudanças em sua rotina, algo a ser destacado é que o fato de ela ser solteira, e ainda morar com os pais, pode facilitar o desempenho de suas atividades diárias, visto que, com o apoio da mãe, as duas dividem as tarefas domiciliares e, sendo assim, não toma tanto tempo dela.

Outro fator que, na concepção de Margarida trouxe mudanças, foi quanto aos tempos livres aos finais de semana que, antes, eram exclusivamente para o lazer e, hoje, se dividem com as obrigações da Universidade:

Sim. Muita mudança, porque querendo ou não, é, eu trabalhava, até no horário de trabalho teve mudança, porque antes eu trabalhava das 8 horas da manhã às 18 horas da tarde. Então, eu tive que mudar o periodo de entrada e de saída devido é..., porque né, a gente depende do ônibus pra poder vir pra faculdade, então eu tive que mudar pra entrar das 7 horas às 17 horas. Ai, na rotina, também houve mudanças porque dai tudo fica mais corrido, você chega, você tem que fazer tudo mais correndo, né. Chega fim de semana, às vezes, assim, você queria sair, queria fazer outra coisa, mas não tem como. Você tem os trabalhos da Universidade pra fazer, às vezes né, as pessoas só podem se reunir naquele dia da semana especifico, no fim de semana, porque as outras pessoas trabalham... Então, mudou bastante a rotina tanto do trabalho quanto da família inteira, né (MARGARIDA).

De forma semelhante, Hortência, que é casada, também relata mudanças em sua vida, inclusive, nos horários das refeições, em que foi necessário fazer ajustes em sua função de dona de casa:

Com certeza muita (risos). É... Ficou um pouco mais tumultuado, a gente teve que preparar os horários, né. Não tem horário pra comer, muitas vezes não dá pra fazer uma janta e a gente tem que se virar com alguma coisinha, mas sempre assim, todo mundo já tá 
consciente, todo mundo já sabe, ninguém reclama mais (HORTENCIA).

De acordo com as reflexões de Pinsky (2012), a boa dona de casa executa os afazeres domésticos genuinamente, lava, passa, cozinha, borda, cuida dos filhos. É a mulher que sabe ser econômica e valorizar o esforço do marido. Embora, grande parte das responsabilidades com a casa e os filhos continue sendo feminina, as mudanças no cotidiano familiar têm feito com que as famílias se adaptem à nova realidade e possibilitando uma maior divisão de tarefas. Silva (2003, p. 41) salienta que "[...] a abordagem de gênero exige uma relação entre o universo micro e macro, envolvendo as relações de caráter familiar e social e, portanto, a análise do espaço privado e o público".

\section{Lazer}

Ao comentar sobre como fica o lazer, com tantos afazeres relativos a trabalhar fora, cursar o ensino superior e cuidar da casa, as participantes da pesquisa revelaram que, apesar de tantas ocupações, elas conseguem tirar um tempo para elas ou para o lazer. Entendem que, na medida do possível, preferem, muitas vezes, sacrificar o sono durante a semana, mas, nos finais de semana buscam estar com a família. Assim, os finais de semana funcionam como uma válvula de escape para suportar a tripla jornada semanal:

Eu, às vezes, deixo o estudo um pouco de lado e acabo pegando mais pro meu lazer mesmo. Por exemplo, eu adoro ir pra fazenda, que é um lugar que me distrai a cabeça e eu mesmo sabendo que eu vou ter mil trabalhos pra fazer no fim de semana, o meu fim de semana é sagrado. Eu vou me espairecer porque senão eu vou enlouquecer. Nem que eu fique de madrugada fazendo no meio de semana, mas meu fim de semana é meu, ninguém me tira (DÁLIA).

[...] consegue sim, como é que eu posso te dizer: você tem que organizar seus horários, nos domingos eu sempre tiro um tempinho pra família, a gente sempre almoça junto na casa da sogra, na casa dos pais, sempre a gente tira um tempinho, sim (HORTENCIA).

[...] a nossa cidade também não tem, né, aquele... Oh! Tantos espaços de lazer pra você ir, então você já não tem nada que te chame, né, assim pra falar: "Ah! Hoje eu vou num parque" ou "hoje eu vou não sei aonde", porque não tem... "hoje eu vou num jardim botânico, hoje eu vou..." Não tem um lugar pra você poder ir. Então assim, quase não te instiga muito a ir nesses locais, porque não tem. Então assim, às vezes de fazer happy hour no fim de semana com a família, uma coisa assim, a gente sempre tenta encaixar alguma coisa (MARGARIDA).

[...] então, assim, é divertido lá em casa, cada um pega um livro e um deita num sofá de perna pra cima, outro deita numa cadeira, outro 
Desafios Vivenciados por Mulheres Universitárias de Mato Grosso do Sul, que

são Mães, Profissionais e Donas de Casa

deita no chão e tá todo mundo lendo e, de repente, um tá comentando o livro do outro, que ninguém tá entendendo nada, e vai explicar e a gente vai aprendendo junto. É engraçado porque o que não sabe fica boiando e vai aprendendo, então, é assim, diz que cada um tem seu momento, tem sua maneira de se divertir, a nossa é essa (GARDÊNIA).

Para Bertollo e Bertollo (2014, p. 05), ser solteira, ser casada, ser mãe, ser idosa faz toda diferença quando se fala em lazer para a mulher. Observando a fala de Margarida, por exemplo, que é solteira, o momento de lazer para ela seria ir ao parque, shopping, happy hour, ou seja, ela busca como lazer atividades que não envolva, de maneira direta, a família. Isso já não acontece com as outras entrevistadas, que em todo tempo suas atividades de lazer estão concentradas em ambientes que suas famílias sejam partes integrantes desse lazer, talvez como forma de amenizar sua ausência durante a semana, elas buscam usufruir o seu tempo livre no cuidado e na companhia da família.

Bertollo e Bertollo (2014, p. 06) reforçam que as mulheres sabem da importância do lazer para sua saúde mental e física, mas, que questões sociais, e até mesmo financeiras, transformam-se em barreiras na hora de procurar novas formas de lazer. As políticas públicas também não dão suporte para o desenvolvimento desse aspecto na vida de muitas mulheres, o que observamos são programas de natureza assistencial que buscam qualificar a mulher para atividades como: artesanato, culinária e costura, sendo assim, nada que valorize o bem estar físico e mental feminino.

Dessa forma, para que não se estabeleça um círculo vicioso e rotineiro, Meneses (2011) afirma que "[...] faz-se necessário uma maior conscientização sobre o lazer, mostrando seus benefícios e as diversas formas de vivenciá-lo, contribuindo para a busca de novas alternativas, fazendo-as saírem do cotidiano dos seus lares".

\section{Trabalho}

Tendo em vista que um dos critérios para a escolha das participantes da pesquisa era o fato de todas terem trabalho formal, elas foram indagadas sobre o tempo de profissão e por que continuaram a trabalhar, mesmo cursando a Universidade. A maioria respondeu que começou muito cedo, devido à necessidade de complementação da renda familiar:

Nossa o porquê é o clássico de todo brasileiro, necessidade (risos) financeira mesmo. Desde quando sempre trabalhei, comecei a trabalhar com 11 anos, né, na adolescência. Aí depois eu casei, tive o meu primeiro casamento, oriundo do meu filho, né, quando eu estava terminando o nível médio em 1999, aí eu fiquei pouco tempo sem trabalhar, mas pouco tempo depois eu voltei trabalhar novamente. E assim desde sempre, antes de ser concursada da prefeitura, esse é o meu segundo concurso da prefeitura, antes de ser concursada na prefeitura, eu trabalhei no laticínio e antes eu trabalhava... Quando eu comecei, eu comecei como babá, doméstica (GARDÊNIA).

Josiane Peres Gonçalves, Janaina dos Santos Ternovoe 
Bom, eu trabalho fora praticamente desde os 14 anos de idade. Bom, pra complementar a renda de casa e porque eu tenho a primeira filha que não é do meu segundo casamento, é do meu primeiro casamento. Então eu não acho justo sobrecarregar, assim, em cima do meu marido. Então acho que eu tenho que ajudar também, né (HORTENNCIA).

Olha, eu trabalho porque na minha casa a minha mãe teve um problema de saúde, então, ela teve que sair do serviço. Então, assim, por um período de uns três, quatro anos, eu que tive que manter a casa e agora que ela conseguiu... esse ano que ela conseguiu o auxílio doença, não é aposentadoria ainda, ela vai receber esse valor, a gente não sabe se é até quando ela aposentar, mas ela está recebendo mensalmente esse valor, então agora já está dando pra mim dar uma tranquilizada. Eu trabalho há cinco anos e sou registrada no mesmo serviço (ROSA).

Podemos notar que, mesmo tendo contraído matrimônio, as entrevistadas continuam no mercado de trabalho e isso se deve a mudança no comportamento social e econômico das famílias. Para Leone (1996), seja qual for a causa da participação da mulher no mercado de trabalho, com certeza ela contribui para o aumento da renda familiar e tende a deixar de ser apenas complementar para se tornar tão importante quanto a do homem. Ou seja, desde muito cedo a mulher busca o trabalho formal para uma emancipação social e financeira.

Por outro lado, Pinsky (2012, p. 508) menciona que, para muitas pessoas, as mulheres que trabalham fora têm dificuldades de conciliar as funções profissionais com as de dona de casa e maternidade, alegando que, "para muitos, casamento e trabalho são incompatíveis [...] porque o envolvimento profissional prejudica a dedicação a casa e família". No caso das mulheres universitárias entrevistadas, elas parecem não se incomodar com essa questão, uma vez que as necessidades econômicas são entendidas como prioridade, elas precisam contribuir com o sustento da família.

\section{Universidade}

Em relação à Universidade, as participantes da pesquisa comentaram sobre o motivo pelo qual elas resolveram cursar o ensino superior. Variados foram os motivos pelos quais essas mulheres decidiram ingressar na Universidade, tais como prazer pelos estudos, carreira, família e finanças:

Olha, eu resolvi entrar pensando no futuro do meu filho, porque quando eu comecei a trabalhar eu já comecei a fazer o Ensino Médio, né, ai eu percebi que eu tinha a necessidade de ter o ensino superior, tanto pra minha qualificação, né, e pra dar um futuro melhor pro meu filho, pra mim mesmo... Porque hoje só o ensino básico não é o fundamental, mesmo pra questão de você arrumar um serviço bom mesmo, não é? (ROSA). 
[...] A primeira faculdade eu fiz, assim, por necessidade de um diploma superior, né, eu queria fazer um concurso na época, que tinha que ter o curso superior. Então, daí, eu fiz a primeira faculdade por necessidade de um diploma, eu sou pedagoga. E daí, agora, só que assim, eu acabei não exercendo por conta de ter passado em outro concurso da prefeitura, nesse que eu atuo agora. E agora, assim, eu estou estudando mesmo e me apaixonei pelo curso depois que comecei a fazer, é claro (GARDÊNIA).

A Universidade, na verdade, já era pra mim tá no $3^{\circ}$ semestre, eu sempre fiquei adiando e eu sempre tive vontade de fazer Pedagogia. Eu já fiz o técnico pra ver se era isso mesmo que eu queria, aí eu gostei do curso quando participei das disciplinas que eu fiz e dos estágios e eu me identifiquei bastante, aí eu resolvi entrar agora. Eu já cursei Serviço Social, aí não gostei. Parei e resolvi fazer Pedagogia novamente (HORTENCIA).

[...] É, eu gosto muito de número, então eu sempre quis cursar Engenharia Civil, né, mas assim devido à questão financeira e a questão também afetiva da família, do lar, de eu ter que me mudar pra outra cidade e tudo. Então, foi assim, minha mãe já tinha feito um curso e ela ficava me incentivando 'Vai, faz o ENEM, faz pra ver o que dá', né? E eu fiz o ENEM e passei e vim fazer, mas, depois que eu comecei o curso, assim... Hoje eu já me identifico bem melhor com o curso do que no começo (MARGARIDA).

Porque o mundo do estudo me encanta, eu adoro estudar (DÁLIA).

É possível perceber, mediante a fala de algumas entrevistadas, que a escolha pelo curso de licenciatura se deu por necessidade, ou pelo fato de elas se sentirem predispostas a atuar nessa área do conhecimento, conforme aponta Louro (2012, p. 450): "afirmavam que as mulheres tinham, 'por natureza', uma inclinação com o trato com as crianças, que elas são as primeiras e "naturais educadoras". Por outro lado, existem mulheres que gostariam de atuar em outras áreas, como foi citado pela entrevistada Margarida, que seu curso dos sonhos é Engenharia Civil, área considerada, socialmente, como sendo masculina.

Partindo do pressuposto que não é tarefa fácil conciliar a vida familiar, profissional e acadêmica, as entrevistadas foram indagadas sobre quais os maiores desafios, enfrentados por elas, durante esse período de ensino superior. As entrevistadas Hortência, Dália, Gardênia e Margarida colocam como dificuldades a adaptação à rotina de ambos os cursos, que acaba por pesar no desempenho como acadêmicas e nos afazeres profissionais e familiares. Para Gardênia e Hortência do $1^{\circ}$ ano, porém, de cursos distintos, algo desafiante é a vivência em sala de aula com pessoas mais jovens. As entrevistadas não mencionam as relações de gênero como desafio e sim a diferença de idade, talvez porque, nas salas de aulas dos cursos de Licenciatura em Ciências 
Sociais e Pedagogia, há a predominância de alunas do gênero feminino, mas, essas mulheres são desde adolescentes que acabaram de concluir o Ensino Médio, até mulheres com mais de quarenta anos, que depois de um tempo parada resolveram voltar a estudar:

Eu, principalmente, porque, assim, devido à idade, maturidade, necessidade de... Porque, assim, ser dona de casa, mãe, profissional. Dai resolve ser acadêmica e você tem um dia todo corrido de trabalho e cuidados e você chega à escola à noite você quer estudar rápido e voltar rápido pra casa, ai você chega numa sala de aula onde tem muitos adolescentes, adolescente gosta de conversar, gosta de... Dai você fica pensando 'Nossa! O que eu tô fazendo aqui? Eu poderia tá em casa que eu teria ganhado mais'(GARDÊEIA).

Os maiores desafios, eu acho, que vem de agora pra frente porque a gente ficou um tempo afastado da escola então, né, você tem certa dificuldade pra pegar do que os outros que saíram, né, que estão recente. Os desafios eu acho que também estão por vir, é como que eu posso dizer, acho eu ainda tá cedo pra falar dos desafios na verdade né, que a gente tá começando, a gente tá meio assustado com as coisas, mas tá sendo bom, estou gostando (HORTÊNCIA).

[...] dificuldade que eu tive mesmo que enfrentar foi de ficar tanto tempo parada e, de repente, você se vê numa outra realidade, porque imagina você tá todo dia num... é cômodo, né, você tá todo dia na sua casa, dá a noite você tá ali, às vezes algum amigo vai chegar pra te visitar, a gente tem o costume, né, de tomar um tererê, ou vai à casa de alguém, ou faz alguma coisa à noite e tal, sai pra algum lugar... E, de repente, você se vê ali, né, diante, né, de uma instituição, onde você tem que ir todos os dias onde você tem regras a cumprir, tem horários para ir, tem horário pra voltar... (MARGARIDA).

Os desafios, eu penso assim, que é na questão de deixar meu o filho sozinho é o que me deixa muito triste, porque é dificultoso pra mim que trabalho e estudo, tem certa dificuldade porque eu tenho que intercalar o trabalho, a faculdade, o filho... E, às vezes, é muito dificil a questão de estágio e, às vezes, eu me culpo muito por, às vezes, estar ausente na questão, né, de dar atenção pra ele. Mas, eu também converso muito com ele, né, explico que tá terminando que vai ser o melhor pro futuro dele, que a mãe está buscando melhoria, sempre tô conversando com ele (ROSA).

Os trabalhos (riso), porque você conciliar fazer trabalho, fazer estágio trabalhando fora, trabalhando dentro de casa e cuidando dos filhos é muito difícil (DÁLIA).

Ao analisarmos a fala da entrevistada Rosa, vemos que a preocupação com filho afeta seu aspecto psicológico e a faz sentir-se culpada, por sua ausência 
devido o trabalho e os estudos, reforçando o que diz Spindola e Santos (2003), que a mulher assume a responsabilidade do bem estar dos filhos e, para isso, ela precisa estar 24 horas ao lado deles, para que, assim, seja considerada uma boa mãe. É notório esse pensamento, quando Rosa diz que explica para o filho o motivo de sua ausência e justifica dizendo que tudo que ela faz é para que ele possa ter um futuro melhor.

Outro ponto considerado como desafio pelas entrevistadas é o fato de ter que conciliar as atividades acadêmicas com o trabalho, uma vez que, nem sempre, há flexibilidade, resultando em dificuldades que precisam ser superadas. Nesse sentido, a entrevistada Rosa relata sobre a fase dos estágios como sendo difícil, porque além dessa atividade, tem que continuar a desempenhar todas as outras funções de mãe, dona de casa, profissional e estudante. Dália, também, fala da dificuldade de conciliar a vida doméstica e profissional com a acadêmica. Todos esses relatos vêm confirmar o que diz Probst (2015), quando revela que a mulher se dedica às atividades profissionais da mesma maneira que o homem, contudo, ela ainda precisa desempenhar suas funções de mãe e esposa nas atividades do lar.

Ao serem questionadas se, em algum momento, as mulheres universitárias haviam pensado em desistir do curso, a maioria disse que sim, alegando problemas pessoais que envolviam trabalho, família e saúde. Tais informações evidenciam que, para haver um bom desempenho acadêmico, a/o estudante de ensino superior precisa estar bem, tanto na vida pessoal, quanto na vida profissional, visto que uma pode interferir na outra. A entrevistada Rosa, por exemplo, que está no final do curso, aponta o choro do filho durante o período que tem que cumprir suas obrigações acadêmicas, como um dos motivos pelos quais pensou em desistir. Paralelamente, os relatos das participantes da pesquisa sinalizam que o ser humano também pode ser resiliente e, sendo assim, ao se deparar com as dificuldades no decorrer do processo ou da sua trajetória, é possível superá-las, a fím de alcançar o seu objetivo:

Já, já pensei, eu pensei em desistir nos estágios porque ficou bem dificultoso e, às vezes, eu chego em casa, e vejo meu filho chorando querendo que eu fique com ele e eu não posso ficar, isso pra mim, eu fico muito triste e já pensei varias vezes de desistir, várias vezes (ROSA)

Bom, sim pensei em desistir no meu segundo semestre, mas não relativo ao curso, relativo a problemas pessoais que eu tive, né (MARGARIDA).

Ao entrar na Universidade, as pessoas logo percebem que terão que desenvolver muitas atividades concernentes ao curso. Sendo assim, perguntamos as entrevistadas se, na opinião delas, a Universidade leva em consideração sua vida social e familiar, no que diz respeito às obrigações do curso. Todas as mulheres responderam que não, pois elas compreendem que a instituição deve tratar todos os acadêmicos de maneira igualitária, não fazendo diferenciação no que diz respeito à vida conjugal, familiar ou profissional dos acadêmicos. Mas, que os professores, por terem conhecimento da realidade dos 
acadêmicos, fazem um planejamento de forma flexível aos alunos e cumprindo, assim, o que a grade curricular determina:

Eu acho que, eu penso que eles não levam, porque se eles forem levar, eles vão ter que generalizar e eles não podem, acho que eles têm que seguir aquele padrão. Então, quem tem familia, tem filho, tem que se adequar, se planejar, se organizar pra seguir esse padrão deles, porque eles não podem ficar pensando, né, em todo mundo. A gente tem que seguir o padrão deles, eu penso assim (ROSA).

Não, a faculdade, não. Alguns professores, sim, a faculdade em si tanto importa, eu sou igual a qualquer um que entrar aqui (DÁLIA).

Eu diria que, em partes, hoje, agora, no terceiro semestre, eu diria que todos os professores têm essa consideração porque... assim, eu não viso, mas a política da Universidade visa, mas dependo dos professores (GARDÊNIA).

Embora a Universidade procure tratar todos os alunos de maneira igualitária, para evitar injustiças, no que se refere ao gênero e à vida pessoal das mulheres estudantes, é preciso considerar que elas já se encontram em situação desigual porque não tiveram oportunidade cursar o ensino superior anteriormente, quando ainda não tinham filhos e nem tantas responsabilidades domésticas e profissionais. Assim, pode-se afirmar que as relações de gênero nas universidades se caracterizam como "[...] importantes elementos para a compreensão da realidade socioespacial contemporânea, caracterizada por uma particular estruturação familiar, instituída nas relações de poder que estão, simultaneamente, nas esferas pública e privada" (SILVA e NABOZNY, 2009, p. 30).

\section{Relação entre a Vida Pessoal, Acadêmica e Profissional}

Questionadas sobre como costumam conciliar a sua vida pessoal, acadêmica e profissional, as entrevistadas responderam que, por mais difícil que seja, arrumam sempre um jeito, e sempre que têm horários livres, elas costumam dedicar-se à família que, durante a semana. acaba sofrendo com a ausência delas. A entrevistada Rosa se desdobra durante a semana com o trabalho e os estudos para dar atenção ao filho aos finais de semana, como forma de compensar sua ausência nos outros dias:

Aos finais de semana eu fico com meu filho e, assim, sempre tento fazer os trabalhos da faculdade ou algum plano de aula, ou alguma coisa assim... no dia de semana mesmo, porque no final de semana eu quero ficar livre pra dar atenção pra ele, porque na semana eu já sou bem ausente, então, final de semana, quando ele tá na casa do pai dele, dos avós eu aproveito pra fazer os trabalhos. Mas, no momento que eu tô com ele, nos finais de semana, eu tento sempre dar atenção pra ele (ROSA). 
Hortência relata que fez a opção por deixar o emprego para poder acompanhar o crescimento do filho que, por ser uma criança pequena, exprime mais cuidados por parte da mãe, que se sente excluída de algumas fases da vida do filho, por não estar o tempo todos ao seu lado. Isso mostra que, por mais que o trabalho traga emancipação para a mulher, se a renda da família é apenas complementar, a mulher acaba por abrir mão do emprego em favorecimento da família:

Na verdade, eu já até pedi as contas do meu emprego e pedi as contas não por conta da Universidade tanto, mas porque eu não tô tendo tempo pra ficar com o meu bebê. Eu acho que eu tô perdendo essa fase, porque da minha primeira filha eu já perdi essa fase e eu não quero perder dele, por ser o último filho e eu não pretendo ter mais filhos, ai eu quero curtir ele pouquinho mais. Eu sinto que ele tá precisando um pouquinho mais de mim, que eu não estou vendo aquele período dele, como o andar dele foi pouco que vi. Acho que meus pais viram mais, a minha filha, o meu esposo do que eu. Então, não estou participando das coisas dele da creche, então eu quero participar mais porque da minha filha eu não tive a oportunidade e eu quero participar mais. Então, eu creio que isso vai fazer com o que eu saia do serviço, mas eu não vou abandonar a faculdade (HORTENNCIA).

Já as entrevistadas Margarida e Gardênia, por terem filhos maiores, não encontram dificuldades no que diz respeito a conciliar suas atividades. Margarida reforça a necessidade em cumprir seu papel de mãe em meio a tantas atividades. Algo interessante na fala de Gardênia é que ela costuma conciliar cada coisa no seu momento e que, para ela, quando um assunto atrapalhar o outro, ela prefere abrir mão de um deles e, em sua opinião, ela prefere sacrificar os estudos, dando prioridade para o trabalho e a família:

[...] a gente tenta conciliar da melhor forma, tento separar alguns horários, né, também porque a vida profissional; acho que totalmente ela já impõe os horários, né, a vida acadêmica ela também já impõe os horários. Então, acho que o que sobra você tem que dedicar a sua família também, né, porque, também, como eu tenho a minha filha, então, eu tenho que dedicar um tempo a ela também, porque ela só tem dez anos, ela ainda tem uma necessidade de um afeto, de um carinho, de um afago da mãe, né, Então, tem que conciliar tudo isso (MARGARIDA)

Olha, o meu esposo costuma dizer que eu sou bipolar (risos...), porque se você misturar tudo não tem como. Eu, particularmente, adotei a prática, desde quando o meu filho era bebê, de personalidade diferente mesmo: eu sou a Gardênia funcionária pública aqui no meu serviço, mas, na minha casa, eu sou a Gardênia mãe e na escola eu sou a Gardênia aluna. Daí, eu preciso lembrar, lá na escola, não, eu sou funcionária, ou eu sou mãe, mas quando não é, 
melhor a gente esquecer, porque senão, não tem como, não tem como você conciliar. Não tem como você vir para o serviço pensando que você tem um trabalho acadêmico, que você tem um filho em casa com algum problema, você não desenvolve no serviço. Então, esses assuntos têm que ficar pra resolver cada um no seu ponto e é lógico que quando você apura muito você precisa deixar alguma coisa de lado, infelizmente, quem acaba sofrendo são os estudos, porque, assim, é... Chega num momento, que nem eu já vivenciei de ter problemas familiares, do tipo saúde, e com o serviço não tem como, porque você precisa do teu salário. Daí, não tem como desistir, não tá dando pra conciliar, você dá uma abandonada nos estudos. É o que sofre, né, infelizmente (GARDÊNIA).

Ainda na fala de Hortência, podemos entender que não se trata de algo definitivo sua saída do trabalho, visto que ela deu prioridade aos estudos que no momento não interferem no cuidado com o filho, ou seja, quando ela vir a terminar a Universidade, seu filho já não será tão dependente dela quanto é na atualidade e, assim, poderá exercer sua profissão. Por outro lado, podemos presumir que Gardênia renunciaria aos estudos pelo fato de ser concursada e ter uma estabilidade no emprego e já possuir uma formação acadêmica, e seu filho já não carece de tantos cuidados, sendo que o mesmo já é um adolescente.

\section{Considerações Finais}

Diante do propósito do presente estudo de investigar os desafios vivenciados por mulheres universitárias que, também, desempenham as funções de donas de casa, mães e profissionais, por trabalharem fora, após a pesquisa realizada com estudantes dos cursos de Ciências Sociais e Pedagogia da UFMS/CPNV, foi possível perceber que essas mulheres conseguem ter muita garra e disposição pra desempenhar suas múltiplas funções.

Vale ressaltar, porém, que essa realidade de a mulher poder estudar e ter vida pública deve-se a tantas outras mulheres de gerações anteriores que, gradativamente, foram rompendo com as imposições sociais nas quais viviam e, durante longos anos, foram conquistando a independência que presenciamos na sociedade atual.

Ao sair das quatro paredes do lar, a mulher se fez ser notada na sociedade e mostra que é capaz de desempenhar funções antes ditas como apenas masculinas. Mostrou que é capaz de ir à busca de seus objetivos sem deixar de ser mulher e feminina. Mostrou que, apesar de a sociedade querer, muitas vezes, calar seus pensamentos, ela também tem opinião e pode construir um mundo mais justo juntamente com os homens, e que luta todos os dias para mudar o pensamento daqueles que a consideram a única responsável pelo sucesso da família.

A pesquisa evidenciou o quanto as mulheres lutam por um espaço no mundo dos homens, não para provar que são melhores que eles, mas, para crescer junto com eles. Em todas as falas de nossas entrevistadas, observamos que elas não buscam o sucesso somente para benefício próprio, mas, sim, para 
o conforto dela e de suas respectivas famílias.

No que diz respeito à Universidade, as entrevistadas demonstraram ser capazes de serem mulheres, donas de casa e universitárias, mas, que a família e o trabalho, normalmente, têm peso maior na hora de fazer as escolhas. Mostraram que é possível, com ajustes na rotina, desempenhar suas atividades acadêmicas, contudo, às vezes, se fazem necessárias algumas renúncias.

$\mathrm{O}$ relato das entrevistadas mostra que as mulheres que desempenham múltiplos papéis não conseguem ter um momento de lazer a não ser no ambiente familiar. Isso é algo preocupante, porque além de assumir inúmeras responsabilidades, as mulheres continuam num círculo vicioso do ambiente domiciliar. Talvez porque se sintam pressionadas por seus familiares e sociedade como um todo, cobrando de si mesmas a responsabilidade pelo bem estar da família.

Diante dos dados obtidos, sugerimos que novas pesquisas sejam desenvolvidas na área, especialmente sobre o que pensam os filhos de mulheres que trabalham e estudam. Dessa forma, seria possível verificar se a cobrança que as mulheres fazem de si mesmas, de não poderem se dedicar à função materna como gostariam, se tem reflexo no comportamento dos filhos, e, consequentemente, no comportamento das novas gerações, visto que cada vez mais as mulheres tendem a ir em busca de novas conquistas na sociedade.

\section{Referências}

AMADO, Tina; BRUSCHINI, Cristina. Estudos sobre mulher e educação: Algumas questões sobre o magistério. Cadernos de Pesquisa, v. 64, p. 4 - 13, 1988.

BARSTED, Leila Linhares; PITANGUY, Jaqueline. Educação formal, mulheres e gênero no Brasil contemporâneo. O Progresso das Mulheres no Brasil 2003-2010. Rio de Janeiro: Cepia, 2011.

BERTOLLO, Sandra Helena J.; BERTOLLO, Mauro. "Gênero e lazer: experiências de cinco gerações de mulheres". In: X ANPED SUL, Florianópolis. Anais... 2014. p. 1- 6.

BRASIL, Ministério de Educação, Instituto Nacional de Estudos e Pesquisas Educacionais Anísio Teixeira. Censo Educação Superior 2013.

CAMPOS, Marta Silva; TEIXEIRA, Solange Maria. Gênero, família e proteção social: as desigualdades fomentadas pela política social. Revista Katálysis, v. 13, n. 1, p. 20-28, 2010.

COZER, Luíza S.; CORINO, Tatiana B.; PÊPE, Tatiana B. "Ações afirmativas dirigidas à proteção da mulher". In: Fazendo Gênero 8 - Corpo, Violência e Poder, Florianópolis. Anais... 2008.

DEL PRIORE, Mary. História das Mulheres no Brasil. São Paulo: Contexto, 1997. 
Desafios Vivenciados por Mulheres Universitárias de Mato Grosso do Sul, que são Mães, Profissionais e Donas de Casa

FREIRE, Eleta de C. Mulher no magistério: Uma luta de embates entre espaço público e espaço privado. Revista Lugares de Educação, v. 1, n. 2, p. 239 256, 2011.

GUEDES, Moema de Castro. A presença feminina nos cursos universitários e nas pós-graduações: desconstruindo a ideia da universidade como espaço masculino. História, Ciências, Saúde, v. 15, p. 117 - 132, 2008.

HYPÓLITO, Álvaro Moreira. Trabalho docente, classe social e relações de gênero. Coleção Magistério, Formação e Trabalho Pedagógico. Campinas, SP: Papirus, 1997.

LEONE, Eugênia Troncoso. Trabalho da mulher e renda familiar na região metropolitana de São Paulo. 1996. Disponível em $<$ www.abep.nepo.unicamp.br/docs/anais/pdf/1996/T96V1A26.pdf $>$. Acesso em 21 Agosto de 2015.

LOURO, Guacira Lopes. Gênero e magistério: identidade, história, representação. In: CATANI, Denice Barbara; et al (Orgs.). Docência, memória e gênero: estudos sobre formação. São Paulo: Escrituras Editora, 1997.

LOURO, Guacira Lopes. Mulheres na Sala de Aula. In: PRIORE, Del Mary; PINSKY, Carla Bassanezi (Orgs.). Historia das mulheres no Brasil. São Paulo: Contexto, 2012, p. $371-403$.

LÜDKE, Menga; ANDRÉ, Marli Eliza Dalmazo Afonso. Pesquisa em educação: abordagens qualitativas. São Paulo: EPU, 1986.

MENESES, Juliano de Souza. A experiência de Lazer por um grupo de mulheres empobrecidas e o seu perfil socioeconômico. 2011. Disponível em $<$ http://repositorio.ucb.br/jspui/bitstream/10869/1108/1/tcc. ARTIGO.pdf $>$. Acesso em 21 Agosto de 2015.

MINAYO, Maria Cecília de Souza. Pesquisa social: teoria, método e criatividade. Petrópolis, RJ: Vozes, 1998.

PADILHA, Ana Caroline de B.; SANTOS, Marinês Ribeiro dos. Pedagogias de gênero em casa \& jardim: A constituição da dona de casa moderna no espaço da cozinha (anos 1950 a 1960). Caderno Espaço Feminino, v. 27, n. 2, p. $73-93,2014$.

PINSKY, Carla Bassanezi. Nova História das Mulheres no Brasil. São Paulo: Contexto, 2012.

PROBST, Elisiana Renata. A evolução da mulher no mercado de trabalho. Instituto catarinense de Pós-graduação. 2015. Disponível em $<\mathrm{http}$ ://www.posuniasselvi.com.br/artigos/rev02-05.pdf $>$. Acesso em 28 Dezembro de 2015.

ROSEMBERG, Fúlvia. Mulheres Educadas e a Educação de Mulheres. In: Josiane Peres Gonçalves, Janaina dos Santos Ternovoe 
Desafios Vivenciados por Mulheres Universitárias de Mato Grosso do Sul, que

são Mães, Profissionais e Donas de Casa

PINSKY. Carla Bassanezi; PEDRO, Joana Maria. Nova História das Mulheres no Brasil. São Paulo: Contexto, 2012.

SPINDOLA, Thelma; SANTOS, Rosângela da S. Mulher e trabalho - A história de vida de mães trabalhadoras de enfermagem. Revista LatinoAmericana de Enfermagem, p. 593 - 600, 2003.

SAFIOTI, Heleieth. A mulher na sociedade de classes: mito e realidade. Petrópolis: Vozes, 1979.

SANTOS, Ramaiane C.; SACRAMENTO, Sandra M. O Antes, o Depois e as Principais Conquistas Femininas. Revista Anagrama: Revista Científica Interdisciplinar da Graduação, v. 5, n. 1, p. 1 - 10, 2011.

SILVA, Joseli Maria. Geografias feministas, sexualidades e corporalidades: desafios às práticas investigativas da ciência geográfica. Espaço e Cultura, n. 27, p. $39-55,2010$.

SILVA, Joseli Maria. Um ensaio sobre a potencialidade do uso do conceito de gênero na análise geográfica. Revista de História Regional, v. 1, p. 31 - 45, 2003.

SILVA. Joseli Maria; NABOZNY, Almir; ORNAT, Marcio Jose. A visibilidade e a invisibilidade feminina na pesquisa geográfica: uma questão de escolhas metodológicas. In: SILVA, Joseli Maria; ORNAT, Marcio Jose e CHIMIN JUNIOR, Alides Baptista (Orgs). Espaço, gênero e feminilidades iberoamericanas. Ponta Grossa: Toda Palavra, 2009, p. 21 - 42.

XAVIER FILHA, Constantina. 'Escola de donas de casa' e a aprendizagem para ser mãe: O ser mulher portuguesa na década de 1950. Quaestio - Revista de estudo e educaçãa, v. 5, n. 2, 2003. Disponível em $<$ http://periodicos.uniso.br/ojs/index.

php?journal=quaestio\&page $=$ article \&op $=$ view $\&$ path $\% 5 B \% 5 \mathrm{D}=1363 \&$ path $\% 5$ $\mathrm{B} \% 5 \mathrm{D}=1348>$. Acesso em 05 Janeiro de 2016.

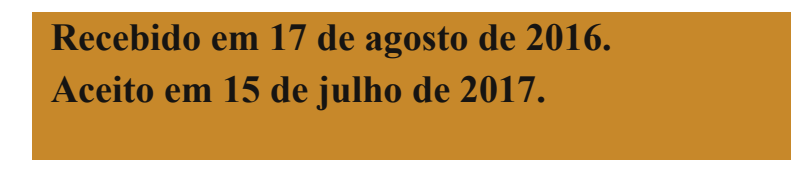

Josiane Peres Gonçalves, Janaina dos Santos Ternovoe 